\title{
The Role of Infliximab Local Injection on Orthodontic Tooth Movement in Experimentally Induced Diabetic Rabbits
}

\author{
Anees M. Mudhir
}

B.D.S and M.Sc in Orthodontic Science - School of Dentistry/Faculty of Medical Science/Department of POP

\author{
Rafah H. Al-Maroof
}

B.D.S., M.Sc., PhD. Oral Histology - Assist. Prof. - Oral Diagnosis Depart.,College of Dentistry,Hawler Medical University

\section{Fadhil Y. Jasim}

B.D.S., C.E.S., D.S.O. Orthod. - Assist. Prof. - Ortho.Depart.College of Dentistry,Hawler Medical University

\section{ABSTRACT}

Introduction: Orthodontic treatment in diabetic patients is usually associated with periodontal disease and bone loss. Proinflammatory tumor necrosis factor-alpha (TNF- $\alpha$ ) level increases in the periodontal tissue during orthodontic treatment. The aim of this study was to investigate the effect of infliximab (tumor necrosis factor- $\alpha$ antagonist) local injection on orthodontic tooth movement in diabetic rabbits.

Methods: Diabetes was induced in 22 male adult rabbits using Alloxan intravenous injection(100mg/kg). The level of blood glucose was controlled using subcutaneous insulin injection(0.5 IU/Kg Body weight). An orthodontic appliance was placed on the upper central incisors of all rabbits for 18 days to create a space between the two teeth. The rabbits were divided into two equal groups, the experimental group received $5 \mathrm{mg} / \mathrm{kg}$ subperiosteal injection of tumor necrosis factor-alpha antagonist (infliximab)in the labial side of the upper central incisors in three time intervals $(0,7,13$ days ) of the study period. The control group received equivalent volume of normal saline in the same location and same time intervals as experimental group. Clinical measurement of the created space were done in $(5,9,13,18)$ days of the studying period .

Results: There was a significantly smaller rate of tooth movement in experimental group than control group represented by smaller spaces created.

Conclusions: Local injection of infliximab decrease the movement of the tooth during orthodontic treatment in experimentally induced diabetic rabbits.

\section{INTRODUCTION}

Diabetes mellitus (DM) is a metabolic disorder characterized by impaired action, secretion of insulin or both, resulting in hyperglycemia. DM has been associated with the occurrence of a series of complications involving the skeletal system like increased risk for occurrence of osteoporosis, poor osseous healing, and impaired bone regeneration potential $^{(1)}$.

A number of oral disorders have been associated with diabetes mellitus like gingivitis and periodontitis that has received the greatest attention ${ }^{(2)}$.

Orthodontic tooth movement is achieved by the remodeling of alveolar bone in response to mechanical loading ${ }^{(3)}$. An alteration of the metabolic state that interferes with bone remodeling can result in a different rate of tooth movement ${ }^{(4)}$.

The need for orthodontic treatment in diabetic patients is usually associated with number of problems related to periodontal degradation, tooth loss, and abnormalities in the development of the jaws ${ }^{(5)}$. Braga et $a{ }^{(6)}$ stated that the specific diabetic changes in the periodontium are more pronounced following orthodontic tooth movement. They used nickeltitanium coiled spring between the maxillary right first molar and the incisors of diabetic and normal mice with force of $35 \mathrm{~g}$. The appliance resulted in greater orthodontic tooth movement in diabetic group than in normal group .

Patients with well-controlled diabetes are not contraindicated for orthodontic treatment (7). Diabetes may exert an effect on the periodontium through cytokine dysregulation. This is supported by a study in which poor glycemic control was significantly correlated with greater production of cytokines with higher cytokine levels in gingival fluid ${ }^{(8)}$. Furthermore, diabetic mice exhibit prolonged inflammation in response to P.gingivalis, which is due in part to TNF dysregulation ${ }^{(9)}$.

Tumor necrosis factor-alpha (TNF- $\alpha$ ) is a potent immunomediator and proinflammatory cytokine that is rapidly upregulated in the brain after injury and secreted by macrophage, monocyte, and neutrophile ${ }^{(10)}$.

In in vivo studies, patients with periodontitis and diabetes were found to have significantly higher levels of local pro-inflammatory mediators such as interleukin- $1 \beta$ and tumor necrosis factor- $\alpha$, compared to systemically healthy individuals with periodontal disease $^{(11)}$.

Pro-inflammatory cytokines, such as TNF- $\alpha$, are thought to play a role in bone remodeling and osteoclast differentiation. In rats and in humans, orthodontic tooth movement increases the levels of TNF- $\alpha$ in the periodontal tissues ${ }^{(12)}$, and reflects changes to multiple components of the periodontium ${ }^{(4)}$.

TNF- $\alpha$ modifying processes directly associated with tooth movement and may also induce mediators of the inflammatory process, which will then influence 


\section{Orthodontics}

osteoclast recruitment and function, suggesting an important role for TNF- $\alpha$ in orthodontic tooth movement ${ }^{(13)}$.

Many attempts have been done to decrease bone resorption during orthodontic treatment using different systemic or local application of medications and the intake of dietary supplements, such as minerals ${ }^{(14)}$, hormones $^{(15)}$, $\operatorname{proteins}^{(16)}$ and immunomodulators ${ }^{(17)}$.

Infliximab is a monoclonal antibody against tumour necrosis factor- $\alpha$. It binds to soluble and membrane-bound TNF-alpha with a high affinity, and inhibits its effect by blocking TNF receptors interaction. Infliximab inhibits bone destruction effectively and treatment with infliximab resulted in significant early decrease in the inflammatory markers $^{(18)}$

In a study done by Liu et al $\mathbf{2 0 0 6}^{(19)}$ when they inoculated Porphyromonas gingivalis into the scalp of diabetic and normoglycemic mice and used Etanercept(TNF- $\alpha$ inhibitor)by two ways of injection, systemically(intraperitoneal) and locally(subcutaneous) in the site of bacteriainduced injery, they noted that the inhibition of TNF- $\alpha$ increases new matrix formation significantly and reduces apoptosis of bone-lining cells in diabetic but not normoglycemic mice. In addition, TNF- $\alpha$ antagonist significantly raised the number of osteoblastic cells to a level that was similar to the normoglycemic group.

In a study on cytokine expression and its inhibition, Zhang et al $2003^{(20)}$ found that after daily intraperitoneal injections of $2 \mathrm{ml}$ of $1 \mu \mathrm{g} / \mathrm{ml}$ soluble receptors to TNF- $\alpha$ (sTNF- $\alpha-\mathrm{RI})$ in Wistar rats induced an inflammation by mechanical injury using a sterilized, flat, needle-like instrument that inserted to $1 \mathrm{~mm}$ in depth on the the mesial gingival margin of the upper left first molars, the results demonstrated that in TNF- $\alpha$ receptor groups the amount of bone and root resorption was significantly reduced following systemic application of sTNF- $\alpha-$ RI.

A study done on Macaca facicularis monkey by Assuma et al $1998^{(21)}$ with induced periodontitis and alveolarbone loss through tying porphyromonas gingivalis-soaked suture ligatures around the posterior mandibular teeth, local injection of soluble receptors to IL-1 and TNF was given three times each week for 6 weeks. The results recorded inhibition of the inflammatory cells in close proximity to bone by approximately $80 \%$, the formation of osteoclasts was reduced by $67 \%$ at the experimental sites compared with that at the control sites, and the amount of bone loss was reduced by $60 \%$.
This study was done to investigate the role of local infliximab (TNF- $\alpha$ antagonist) injection on orthodontically moved teeth in experimental induced controlled diabetic rabbits.

\section{METHODS}

This study used 22 male local breeded rabbits weighing $1.5-2 \mathrm{~kg}$. At the beginning of the experiment, all animals were kept under standardized laboratory conditions of light-and-dark schedule and relative humidity and fed ad libitum with commercial pellets and water from thick-walled glass dishes. Diabetes was induced in all rabbits by a single dose of intravenous (lateral ear vein) injection of alloxan $100 \mathrm{mg} / \mathrm{kg}$ (fig.1), then immediately the animals were injected by $10 \mathrm{cc}$ of glucose $20 \%$ subcutaneously and then $10 \mathrm{cc}$ of glucose every 4 hours for 24 hours to prevent hypoglycemic convulsion. Drinking water of the animal was substituted by glucose solution 5\% for 24 hours to prevent hypoglycemia ${ }^{22}$. Fasting blood glucose was evaluated every morning for 7 days postinjection using Accu-ChekActive monitoring system. Alloxan-injected rabbits were considered to have diabetes if fasting glucose levels were $>300 \mathrm{mg} / \mathrm{dL} .{ }^{1,4}$.

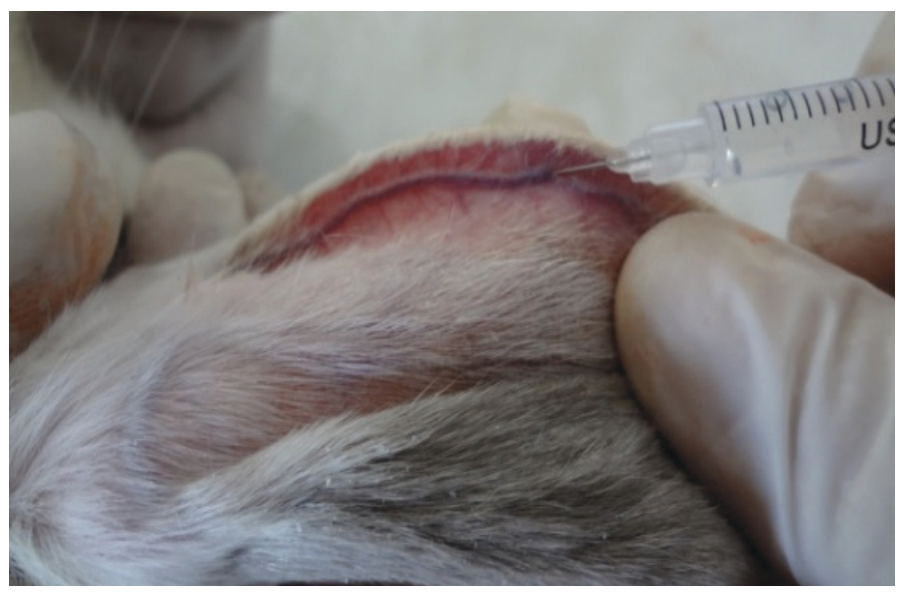

Figure 1:Intravenous (lateral ear vein) injection site of Alloxan

After confirming diabetes in the rabbits, insulin treatment was started by subcutaneous injection of 0.5 IU/Kg body weight every 48 hours in the morning (22). The controlled diabetic rabbits were left for 8 weeks before performing the orthodontic procedure in order to give sufficient time for diabetes mellitus to affect the body tissues ${ }^{(5)}$. After 8 weeks, rabbits were anaesthetized by intramascular injections of xylazine $2 \%(4 \mathrm{mg} / \mathrm{kg} \quad$ B.W. $)$ and Ketamine hydrochloride $(40 \mathrm{mg} / \mathrm{kg} \mathrm{B} . \mathrm{W})$ mixture in order to fix the orthodontic appliance $^{(22)}$. Orthodontic appliances were placed for all rabbits for about 18 days. They consisted of two mini buccal tubes bonded to the labial surface of the upper central incisors vertically positioned parallel to long axis of the incisors in the cervical third of 
clinical crown. L-shaped wire consisted of 2 pieces of $0.017 * 0.025$ inch stainless steel wires, was inserted in the both tubes. The force was applied by light strength nickel-titanium open coil spring which was fitted over the two horizontal wires sections between the two upper central incisors(fig. 2and3). The force level after activation was approximately $35 \mathrm{gm}$ measured using Bolye gauge. This force resulted in distal movement of each upper central incisors gaining median space between the two central incisors.

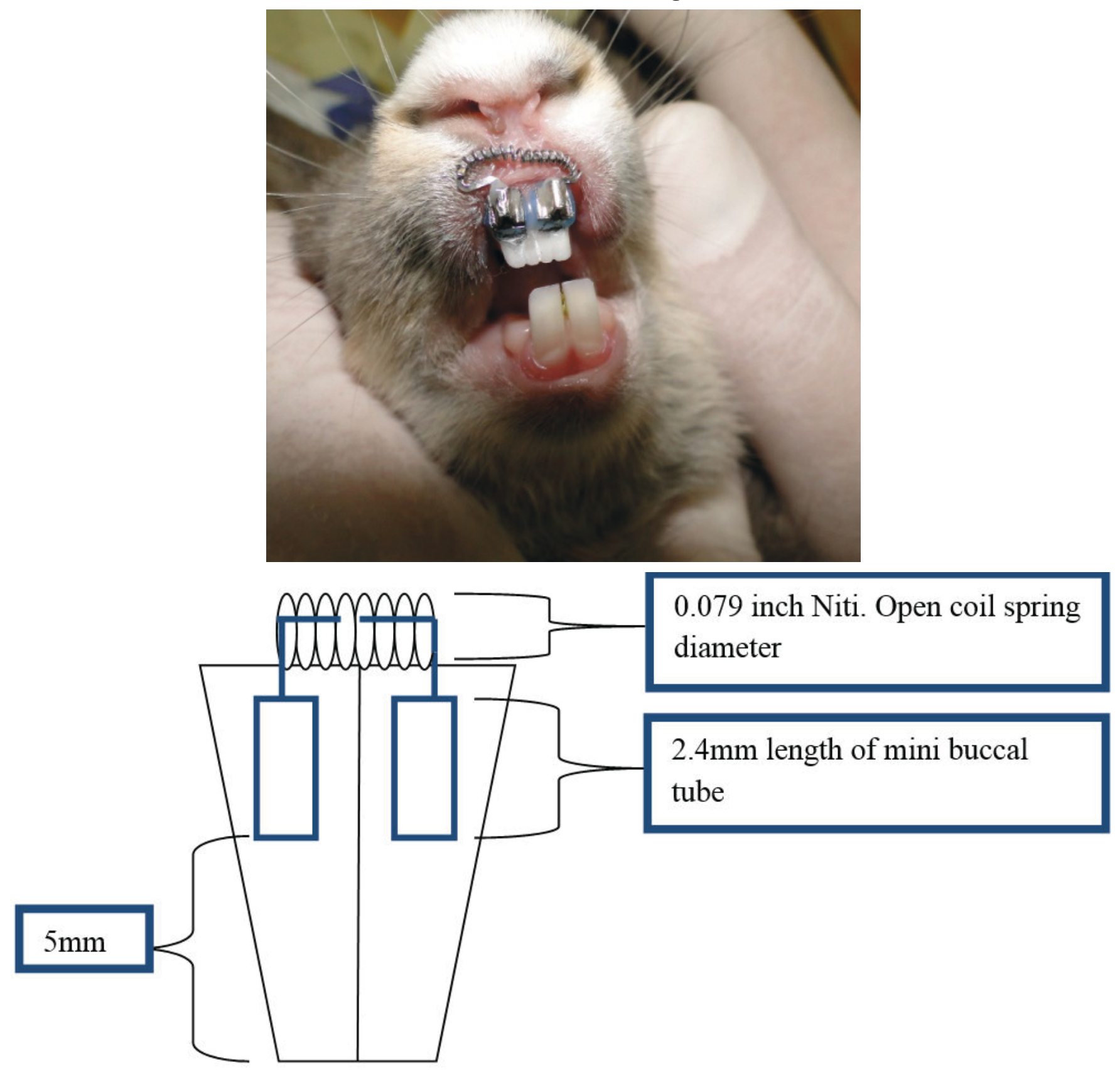

Figure.2: Orthodontic appliance on upper central incisors before activation

Figure 3: Diagram showing the orthodontic appliance used in the study

The rabbits were divided equally into 2 groups (11 rabbits for each): an experimental group which received subperiosteal injection of $0.1 \mathrm{ml}$ of TNF- $\alpha$ antagonist (infliximab $5 \mathrm{mg} / \mathrm{kg}$ ) in the labial side cervically ${ }^{(23)}$. The remaining 11 rabbits were considered as a control group which received $0.1 \mathrm{ml}$ normal saline injection in the same site as in the experimental group(fig.4). The local injection of both infliximab and normal saline were given in three different time intervals $\left(1^{\text {st }}, 7^{\text {th }}\right.$ and $13^{\text {th }}$ day) following insertion of the appliance. To quantify and record the amount of tooth movement, four measurements were performed for each rabbit by measuring the distance between the two mid point of the mesial surface at 


\section{Orthodontics}

cervical line of central incisors at $\left(5^{\text {th }}, 9^{\text {th }}, 13^{\text {th }}, 18^{\text {th }}\right.$ point was chosen in order to stick to a fixed point day) using digital vernier sensitive to $0.01 \mathrm{~mm}$. This during measurement.

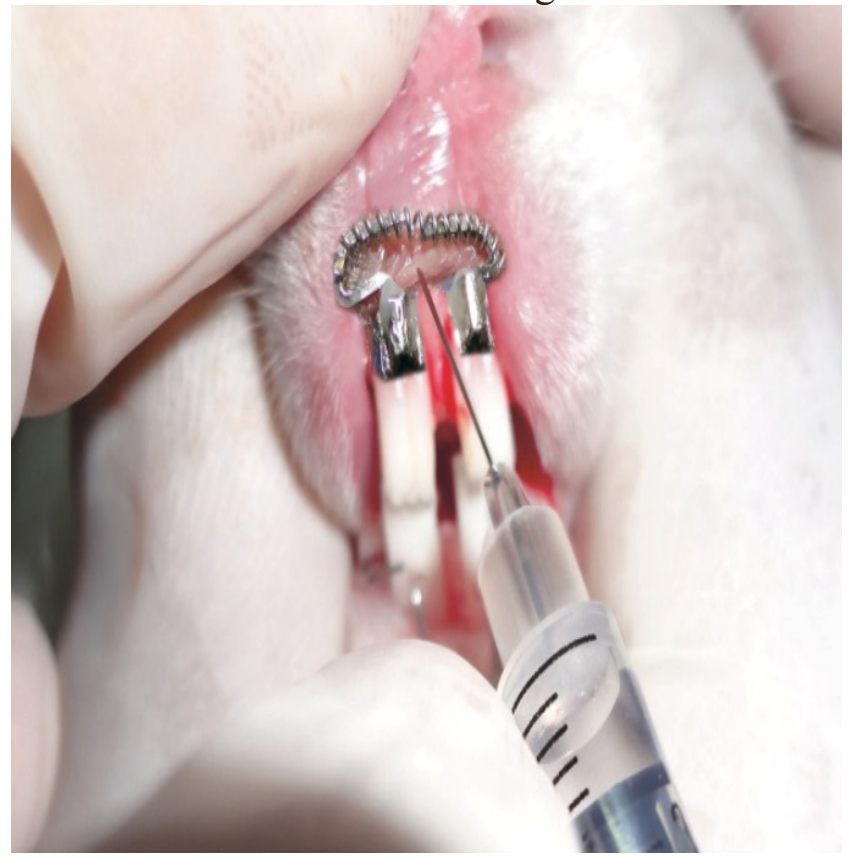

Figure 4: Infliximab and normal saline injection site

Descriptive statistics: means and standard deviations were calculated for both groups. Unpaired student t-test, showing differences in means of spaces between control group and experimental group at different times with standard deviation(SD) for each group. Measurements were in $\mathrm{mm},(\mathrm{P}$ value $\leq 0$.05 was considered statistically significant).

\section{RESULTS}

The insertion of the designed orthodontic appliance resulted in distal movement of the two central incisors with minimum distortion for the gingival tissue and for the appliance in both experimental and control group. (fig 5)

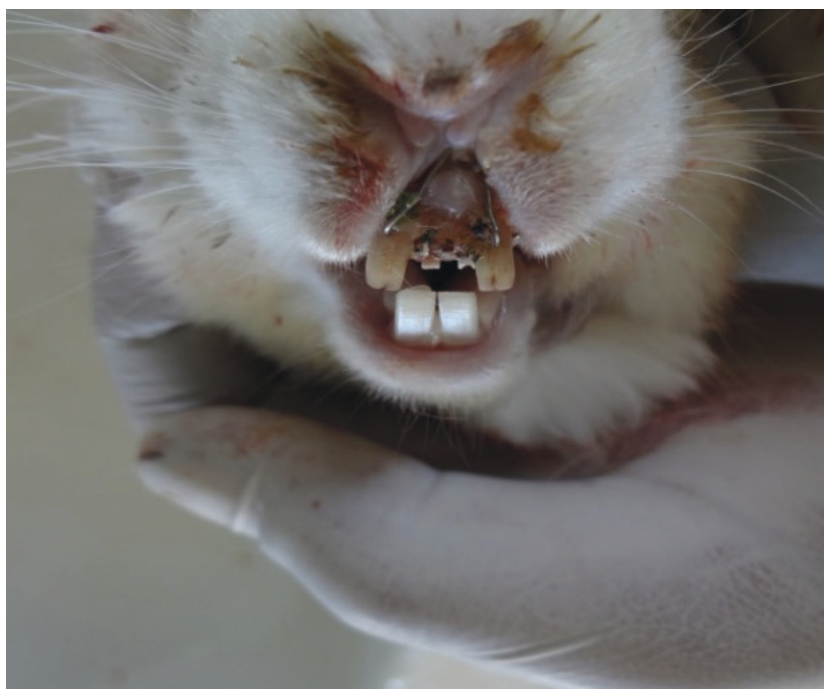

Figure 5:Orthodontic appliance on upper central incisors at the end of the study.
The injection of infliximab in the labial side of orthodontically moved teeth resulted in obvious changes which were recorded and measured clinically. The statistical analysis of the clinical measurement in $\operatorname{day}(5$ and 9) revealed a highly significant difference between experimental and control groups $(\mathrm{P}<0.001)$. While there was very highly significant difference in the mean of the space between the two groups in day (13 and 18), The mean space was(1.909 $\pm \mathbf{0 . 4 5 9} \mathrm{mm}$ )in experimental group in day 5 , while in control group it $\operatorname{was}(\mathbf{2 . 5 5 4} \pm \mathbf{0 . 5 0 9} \mathrm{mm})$. In day 9 , the mean space was $(\mathbf{2 . 7 9 1} \pm \mathbf{0 . 5 0 5} \mathrm{mm})$ in experimental (infliximab given)group, while in control group it was $(\mathbf{3 . 4 3 6} \pm \mathbf{0 . 4 0 6} \mathbf{m m})$. In day 13 the mean space $\operatorname{was}(\mathbf{3 . 7 4 5} \pm \mathbf{0 . 5 0 3} \mathrm{mm})$ in experimental group, while in control group it was $(\mathbf{4 . 5 5 4} \pm \mathbf{0 . 3 7 8} \mathrm{mm})$, where in day 18 the mean of space in the experimental group was(4.591 $\pm \mathbf{0 . 5 0 3} \mathrm{mm})$, while in control group was $(\mathbf{5 . 6 1 8}$

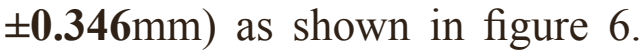

From the statistical data and from figure 6, it is obvious that the experimental group which received infliximab injection showed less tooth movement than the control goup. 


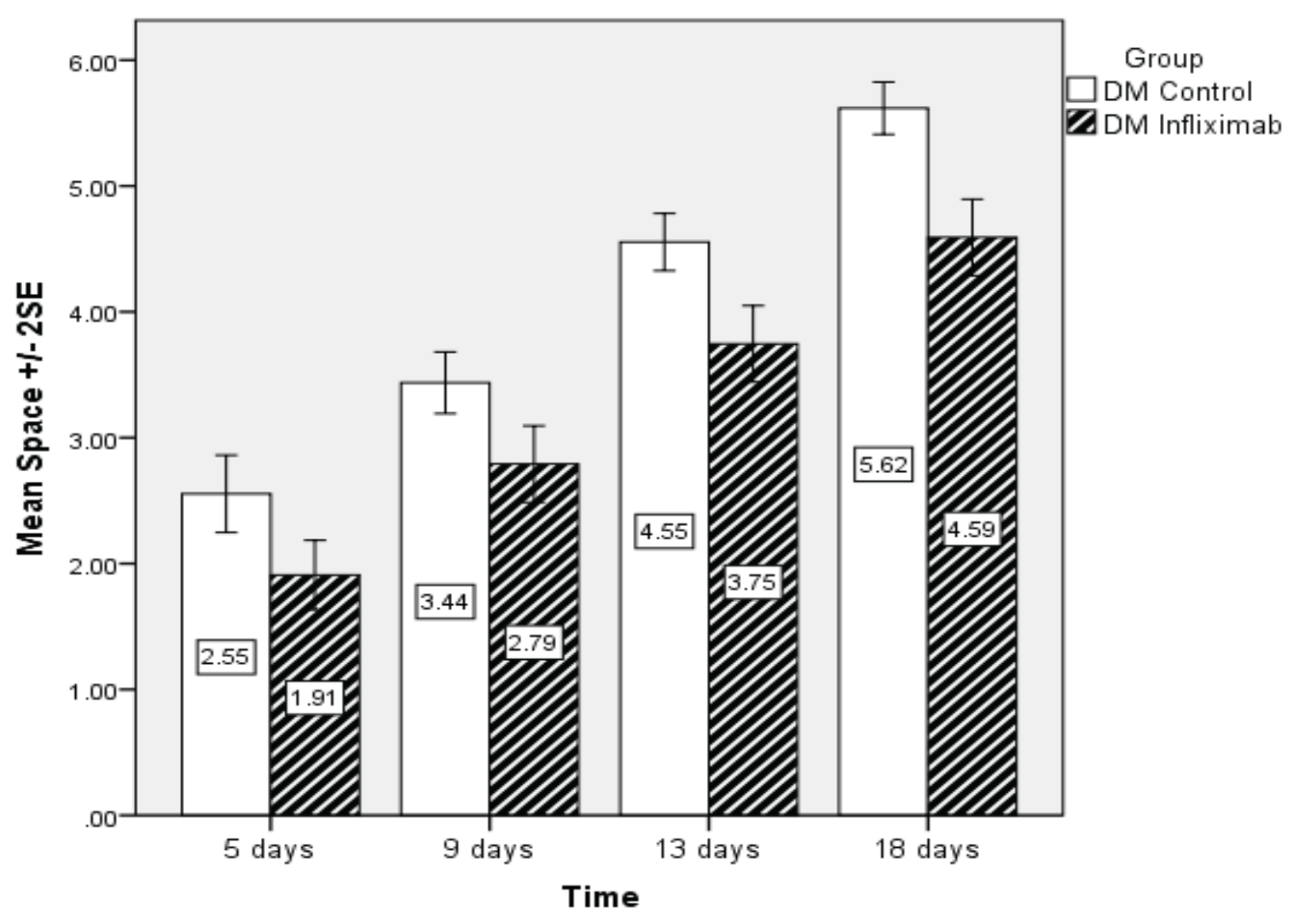

Figure 6: Unpaired student t-test of means and standered deviation $( \pm S)$ of spaces between the two maxillary incisors in both controls and infliximab(experimental) group.

\section{DISCUSSION}

Orthodontic tooth movement occurs by the remodeling of alveolar bone as a result of the force that is exerted on the periodontium ${ }^{(6)}$. In this study, a nonhuman primate model was used to assess the effect of local administration of TNF- $\alpha$ antagonist (infliximab) on the rate of tooth movement in diabetic model in an attempt to interfere with cytokines which are usually elevated during orthodontic tooth movement ${ }^{12}$ and diabetes mellitus ${ }^{(11)}$. To the best of our knowledge there is no previous clinical study on the effect of local infliximab injection on orthodontic tooth movement especially in diabetic model. The results of this study were comparable with those obtained from rats with experimentally induced tooth movement following a constant tipping force of $0.5 \mathrm{~N}$ on upper first molar. The studied animals received daily intraperitoneal injection of $2 \mathrm{ml}$ of $1 \mu / \mathrm{ml}$ of soluble receptors to TNF- $\alpha$ and IL-1, The amount of tooth movement after 3,6,9 and 12 days was reduced especially for the group treated with receptors to TNF- $\alpha$ by approximately 50 persent ${ }^{(24)}$.
An increase in the expression of TNF- $\alpha$ was observed in periodontal tissues surrounding teeth of diabetic mice more than in normoglycemic mice at 12 and 72 hours of orthodontic appliance mechanical loading which exhibited greater orthodontic tooth movement and a higher number of osteoclasts during histomorphometric analysis $^{(6)}$.

Another comparable study done by Andrade et al $2007^{(12)}$ on a nonhuman primate model which use the orthodontic appliance of NiTi coil spring between the maxillary right first molar and the incisors in Wild-type mice(WT)and p55-or TNFRI deficient mice ( $\mathrm{p} 55^{-/-}$). The levels of TNF- $\alpha$ and chemokines were evaluated in periodontal tissues with a significantly smaller rate of tooth movement, and lower number of TRAP-positive osteoclasts in $\mathrm{p} 55^{-/}$mice than that observed in Wild type mice.

The results of thr present study demonstrate that the local injection of infliximab caused a significant reduction in tooth movement in day 5 and day 9, which is considered to be due to 
bone resorption by osteoclasts, while there was a high significant difference between the two groups at the day $13^{\text {th }}$ and $18^{\text {th }}$ revealing that in diabetic group, the increasing bone resorption after orthodontic force application was sustained for longer time. This finding agrees with $\mathbf{L i}$ et al $2010^{(4)}$ study on remodeling of periodontal ligament in diabetic rats. They found markedly increase in osteoclasts in the PDL at the edge of the alveolar bone in the diabetic groups after application of orthodontic force and peaked at day 7. This increase was returned to a normal level gradually in the normal group. However, in diabetic animals, the elevated numbers of osteoclasts were sustained for a longer time under the same force, leading to extended period of the bone destruction. There was a significant difference between the experimental and control groups at day 14 reflecting a large decline in osteoclast number in the normal group versus a small decrease in the diabetic group.

When alveolar bone loss is induced, there is a dramatic increase in leukocyte recruitment in close proximity to bone. The presence of blockers to IL-1 and TNF, decreases the recruitment of leukocytes substantially. This suggests that bone loss is initiated when the inflammatory stimulus spreads to the deep gingival connective tissue, stimulating the recruitment of leukocytes. Thus, blocking TNF- $\alpha$ activities may inhibit bone loss both directly and indirectly; the latter occurring via decreased recruitment of mononuclear cells in the area of bone ${ }^{(21)}$.

In this study, the tooth movement in control group was increased steadily until day 18 and there was a highly significant difference at this day between the control group and the experimental group, this may reflect the time accumulation effect of infliximab at the end of orthodontic movement in experimental group .

Our results demonstrated that diabetic rabbits with infliximab represented an increased tooth movement, this may be due to the inhibition of TNF- $\alpha$ leading to increase in new bone matrix formation and a significant reduces in apoptosis of bone-lining cells in diabetes, and, consequently, a greater number of osteoclasts and bone resorption ${ }^{(25)}$, in addition, TNF- $\alpha$ antagonist significantly raised the number of osteoblastic cells and controlling the production of chemokines and osteoclasts $^{(12)}$.

The decreasing in tooth movement in the experimental group may be related to decrease in bone resorption, since infliximab binds to soluble and membrane -bound TNF- $\alpha$ with high affinity, impairing the binding of TNF- $\alpha$ to its receptor ${ }^{(26)}$. Another action for infliximab which may play a role in the reduction of the inflammatory reaction through killing cells that express TNF- $\alpha$ through antibody-dependent and complement-dependent cytotoxicity ${ }^{(27)}$.

The clinical result of this study need to be confirmed histologically and ultrastructurally prior to the recommendation of using local infliximab injection as an adjunctive in orthodontic treatment to reduce tooth movement especially in anchorage tooth or to control tooth movement in medically compromised patients.

\section{REFERENCES}

1. Retzepi M, Lewis MP, Donos N. Effect of diabetes and metabolic control on de novo bone formation following guided bone regeneration. Clin. Oral Implants. Res. 2010 ; 21:71-79.

2. Rother KI. "Diabetes treatment- bridging the divide".N Engl J Med. 2007;356: 1499-1501.

3. Krishnan V, Davidovitch Z. Cellular, molecular, and tissue level reactions to orthodontic force. Am J Orthod Dentofacial Orthop. 2006;129:1-32.

4. Li X, Zhang L, Wang N, Feng X, Bi L..Periodontal Ligament Remodeling and Alveolar Bone Resorption During Orthodontic Tooth Movement in Rats with Diabetes. Diabetes Technol Ther. 2010 ;12:65-73.

5. Villarino ME, Lewicki M, Ubios AM. Bone response to orthodontic forces in diabetic Wistar rats. Am J Orthod Dentofacial Orthop. 2011;139:76-82.

6. Braga SM, Taddei SR, Andrade I Jr, Queiroz-Junior CM, Garlet GP, Repeke CE et al. Effect of diabetes on 


\section{Orthodontics}

orthodontic tooth movement in a mouse model. Eur J Oral Sci.2011; 119: 7-14.

7. Luc B, Marc B, and Guy W.Orthodontic Considerations in the Diabetic Patient,Sem in Orthod 2004;10:252-258.

8. Engebretson SP, Hey-Hadavi J, Ehrhardt FJ, Hsu D, Celenti RS, GrbicJT, et al. Gingival crevicular fluid levels of interleukin-1betaand glycemic control in patients with chronic periodontitis and type 2 diabetes. J Periodontol 2004;75:1203-1208.

9. Naguib G, Al-Mashat H, Desta T, Graves DT. Diabetes prolongs the inflammatory response to a bacterial stimulus through cytokine dysregulation. $\mathrm{J}$ Invest Dermatol.2004;123:87-92

10. Van Doornum S, McColl G, Wicks IP. Tumour necrosis factor antagonists improve disease activity but not arterial stiffness in rheumatoid arthritis. Advance Access publication, Rheumatol(Oxford) . 2005; 44:1428-1432.

11. Janet H. Southerland; George W. Taylor, and Steven Offenbacher. Diabetes and Periodontal Infection: Making the Connection. Clin Diabetes.2005; 23:171-178.

12. Andrade I, Jr., Silva TA, Silva GAB, Teixeira AL, Teixeira MM.The Role of Tumor Necrosis Factor Receptor Type 1 in Orthodontic tooth movement. J Dent Res 2007; 86 (11): 1089-1094.

13. Yoshimatsu M, Shibata Y, Kitaura H, Chang X, Moriishi T, Hashimoto F et al. Experimental model of tooth movement by orthodontic force in mice and its application to tumor necrosis factor receptor- deficient mice. J Bone Miner Metab: 2006 24:20-27.

14. Sabuncuoglu FA and Esenlik E. Influence of drugs on orthodontic tooth movement. Pakistan oral dent j 2010;30: 398-401.

15. Ong CK, Joseph BK, Waters MJ , Symons AL. Growth hormone receptor and IGF-I receptor immunoreactivity during orthodontic tooth movement in the prednisolone-treated Rat. Angle Orthod 2001; 71: 486493.

16. Kim JY, Kim

BI, Jue

SS, Park

$\mathrm{JH}$

, Shin JW. Localization of osteopontin and osterix in periodontal tissue during orthodontic tooth movement in rats. Angle Orthod 2012; 82: 107-114.

17. Gameiro GH, Pereira- Neto JS, Magnani MB, Nouer DF.The influence of drugs and systemic factors on orthodontic tooth movement. J Clin Orthod; 2007 41:73-78.
18. Korczowska I, Lacki JK, Hrycaj P. Influence of Infliximab on Cytokines Network and Markers of Bone Remodeling in Rheumatoid Arthritis Patients, Yonsei Med J 2013 ; 54:183188.

19. Liu R, Bal HS, Desta T, Behl Y, Graves DT.Tumor Necrosis Factor- $\alpha$ Mediates Diabetes-Enhanced Apoptosis of Matrix-Producing Cells and Impairs Diabetic Healing, Am J Pathol(2006); 168: 757-764.

20. Zhang D, Goetz W, Braumann B, Bourauel C, Jaeger A. Effect of soluble receptors to interleukin-1 and tumor necrosis factor alpha on experimentally induced root resorption in rats. J Periodontal Res. 2003;38:324-332.

21. Assuma R, Oates T, Cochran D, Amar S, Graves DT. IL-1 and TNF antagonists inhibit the inflammatory response and bone loss in experimental periodontitis. J Immunol.1998;160:403-409.

22. Ibrahim S Rudayna.Effect of low energy laser irradiation on bone healing around intra osseous titanium implant in experimentally diabetic rabbits(2003). Oral histology and biology $\mathrm{PhD}$ thesis. University of Baghdad.

23. Triantafillidis JK, Papalois AE, Parasi A, Anagnostakis E, Burnazos S, Gikas A et al. Favorable response to subcutaneous administration of infliximab in rats with experimental colitis. World J Gastroenterol 2005;11:68436847.

24. Jäger A, Zhang D, Kawarizadeh A, Tolba R, Braumann B, Lossdörfer S, Götz W. Soluble cytokine receptor treatment in experimental orthodontic tooth movement in the rat. Eur J Orthod. 2005;27:1-11.

25. Rongkun Liu, Harbinder S. Bal, TesfahunDesta, YugalBehl, and Dana T. Graves.Tumor Necrosis Factor- $\alpha$ Mediates Diabetes-Enhanced Apoptosis of Matrix-Producing Cells and Impairs Diabetic Healing. Am J Pathol. 2006; 168: 757-764.

26. Olsen NJ.and Stein CM. New Drugs for Rheumatoid Arthritis. N Engl J Med 2004;350:2167-79.

27. Scallon BJ, Moore MA, Trinh H, Knight DM, Ghrayeb J. Chimeric anti-TNF-alpha monoclonal antibody cA2 binds recombinant transmembrane TNF-alpha and activates immune effector functions. Cytokine 1995;7:251-259. 